\title{
REFLECTIONS ON THE TREATMENT OF LEPROSY IN INDIA
}

\author{
by Padmasri Dr. IsaAc SANTRA, \\ Honorary Supt., Hatibari Health Home, \\ Sambalpur Dist., Orissa, India.
}

The Mahabharata describes the battle between the Pandavas and the Kauravas and this story is in the consciousness of all the people in India. The Pandavas represent the good forces which fight against the Kauravas, the bad forces, and convert the world from evil and bring back to it grace, and happiness, and progress. By the transfer of the idea to leprosy the attack on the human body by the Kauravas in the shape of leprosy bacilli is opposed by the Pandavas, expressed in the forms of faith, obedience, diet, exercise, and patience.

Diet in India has great importance and there is great variation. The Punjab has the best general diet and there the incidence of leprosy is lowest in India, and the idea has grown up that countries which have a predominantly rice diet, such as South India, Burma, China, and Japan, have more leprosy. In my childhood the calcium deficiency of rice was compensated for by mixing in black gram which contains twice as much calcium as wheat. Jagannath teaches many things about diet including the utilisation of the red coating of rice and the value of the addition of leafy vegetables. The medicinal value of green vegetables is well recognised in India. With Brahmins it is a rule to take green vegetables every day. Also in India the value of products from the cow is understood. Much dietary information is contained in the customs and writings of the Hindu religion.

I think that the chief factor in the prevention of leprosy is to provide proper well balanced diet to the masses. Exercise is also of great importance and the rich in particular tend to avoid this. I remember the case of a rich woman who improved after I had succeeded in tricking her into getting up and going to the temple every day walking five miles. Also in leprosy treatment of today one should try to get the patient to understand the value of patience and persistence. Modern drugs which I have used include hydnocarpus oil, DDS, thiosemicarbazone, INH, and SU 1906. My experiences of these may be summarised as follows:

Iodised ethylesters of hydnocarpus oil $1 \%$ are very useful when given intradermally to the macules of leprosy, in high doses, if possible 20 to 30 c.c. Iodised esters $10 \%$ are useful if injected at the side of the thickened nerves and at the side of the trophic ulcers, and if applied to ulcers inside the nose. Lepromatous nodules disappear in a few weeks if carbolised ethylesters $10 \%$ are injected in the nodules. For out-patients intramuscular injections are given at fortnightly intervals of 1 part DDS mixed with 5 to 10 parts of ethyl 
hydnocarpate in doses of up to 10 c.c., which means that the patient gets $2 \mathrm{~g}$. of DDS per injection.

I give DDS with slow induction of dosage from $10 \mathrm{mgm}$. to $50 \mathrm{mgm}$. in three months, and 100 to $300 \mathrm{mgm}$. over the next two or three years. Reaction is caused by over-dosage, shown by pruritis, sleeplessness, crops of new macules, neuritis and fever.

Thiosemicarbazone is available in India as Novozone and I have found it very useful, and it should be given to cases who cannot tolerate DDS. I give $50 \mathrm{mgm}$. a day and never exceed $100 \mathrm{mgm}$. a day.

INH is best in conjunction with DDS and the combination promises better in results than DDS alone. The dosage is 50 to $100 \mathrm{mgm}$. daily.

The diphenylthiourea, Ciba 1906, promises to be a serious rival to DDS as it is very active and has no toxic side effects. I give a dose of 250 mgm. daily.

I have also used streptohydrazone, which is a combination of streptomycin and $\mathrm{INH}$ and it is good for reactional use. I also used Camoquin for acute lepra reaction and hyalase for nerve reaction. Reactions were also helped by injections of calcium gluconate and potassium antimony tartrate. Vitamin $\mathrm{B}_{1}$, vitamin $\mathrm{C}$, and $25 \%$ glucose all mixed and given intravenously each alternate day for six occasions has been used. Recently I have used a combined tablet of DDS, thiosemicarbazone, INH, vitamin $\mathrm{B}_{1}$, and iron sulphate, called Isoniasulfazone. 